\title{
The impact of electromagnetic waves at the full moon on some physiological changes among the students of the Faculty of Sport Sciences at Mu'tah University
}

\author{
Dr. Baker Sulaiman Thuneibat \\ Mutah University \\ Email: Ana_baker1980@yahoo.com
}

Doi:10.5296/jsr.v5i1.4839

URL: http://dx.doi.org/10.5296/jsr.v5i1.4839

\begin{abstract}
This study aims to identify the impact of electromagnetic waves at the full moon on some physiological changes among the students of the Faculty of Sport Sciences at Mu'tah University. The study sample consisted of 20 students from the Faculty of Sport Sciences at Mu'tah University. Many statistical methods have been used in order to answer the questions of the study (Means, standard deviations, T-Test Independent Samples, Pearson correlation coefficient. The results of (T-Test Independent Samples) for the significance of the pre and post difference showed that there are statistically significant differences for the variables of (heart pulse, blood glucose, systolic pressure and diastolic pressure). The results of Pearson correlation coefficient test for the pre and post measurement also showed that there are statistically significant differences for the physiological variable of (blood glucose) with regard to the variable of age. The study recommended not to rely on the reading of the heart pulse during the days of the full moon as an indicator of the heart pulse, especially for females. The study also recommends to conduct similar studies in different places of hot and cold climates or high and low altitudes .
\end{abstract}

\section{Introduction}

Since the earliest periods of the time, man started studying the sky and its contents, he was driven by the metaphysical conviction that the sky has an absolute control over the earth, Man also used to believe that the nature is one and the energy that drives everything is also one. Thus, every movement in this universe has its impact and consequences on man and his surroundings. The effect of the moon on the human being is constant throughout the ages, and most of the civilizations contain references to this subject although they differ with regard to the importance of the impact that the planets have on man. (Mohsen, 2010)

Man is influenced by the powers of attraction of electromagnetic waves which organize and regulate the movement of the whole universe; where the gravitational force that comes from the center of our galaxy overweighs the electromagnetic energy that is emitted from the core of the earth beneath our feet by more than ten thousand times. The moon is 
also considered as the nearest celestial object to the earth; it affects all the living beings more than any other planet. The influence of the moon is clear and evident by the phenomenon of tides of oceans and seas, and this is well-known to man since the ancient times, but its impact on man, animals and plants wasn't known until recently. (Sa'adia , 2013)

It has been scientifically proven that the moon affects the activities and behaviors of the human beings in an evident and significant degree. When the moon is complete it causes a mental disorder for some people making them closer to insanity in which those people may cause harm to themselves and to others without realizing that, but after a while the moon phase changes, those people return back to their normal situation. The moon also affects the plants at the times of their cultivation harvest and in the seasons of fertilization. It also affects animals in the times of fertilization. Just as the moon draws the water of seas and oceans, it also affects the liquids inside the human body, animals and plants in which it changes the combination and efficiency of liquids in the human beings, such as blood, secretions of glands, and so on since the human body is composed of about $70 \%$ of water.( , 2012)

Researchers in the Center for Health Sciences at the University of South Florida (2004) within their scientific reviews for the relationship between the full moon organic diseases have stated that, there are many medical studies that attempted to understand the relationship between the phases of the appearance of the moon and the injuries of heart strokes, the birth rates, and the attempts of committing suicide, as well as the high need to admission to hospitals as a result of irritation state of the psychiatric patients and epileptic seizures attacks. Those researchers emphasized that the results of those studies did not find any relationship between the lunar phases and the occurrence of those pathological conditions.

As it is physically known, the moon affects the earth's magnetic field, and this effect causes troubles to people whose mental balance breaks down. In fact, the human being is like an electric machine; where the pineal gland in the human brain acts as a magnetic pole, so that it is affected by the cyclical cosmic changes that result from the nearby celestial objects, as in the case of the moon's gravity. These factors contribute to deepening the imbalance and emphasize the conflicts that exist in the human beings, The studies have also indicated that more than $80 \%$ of bleeding cases take place in the second and the third quarters of the lunar month and this is due to the agitation of liquids in the human body. some physicians avoid surgical operations at the full moon nights and delay these operations to the dark nights. (AlNoaimi, 2005)

Doctor Leiber , a psychologist in Miami in the united states reported that there is a strong relationship between the human aggression and the lunar cycle, especially for alcoholics, accidents predisposed, people of criminal tendencies and those who suffer from mental and emotional instability. Leiber explains his theory by saying that the human body is like the earth surface in which it is composed of $80 \%$ of water, while the rest $20 \%$ is 
composed of solid materials. Therefore, he thinks that the moon gravity that causes tides in seas and oceans also causes a tide in our bodies at the time of full moon during the white days when the blood irritates and reaches its highest limits. Thus, all the sediments and impurities that are deposited on the walls of the deep and surface blood vessels move, so when the moon starts to recede during the $\left(17^{\text {th }}-27^{\text {th }}\right)$ days of the lunar month, it becomes possible to take out the blood which is mixed with impurities (Al- Noaimi, 2005)

Many recent studies, such as the study of the University of Leeds, UK which illustrates that the attendees of the external clinics are increasing by $3.6 \%$ at the night of full moon - while surgeons deal with three more patients on average. The Institute of immune diseases in Bratislava in Slovakia finds out that the incidence of acute asthma, during the last 22 years, increases to the highest values in the middle of the month and then decreases gradually until the end of the month.

The study which was recently published by the British journal, the independent- based on the birth dates of 1400 babies -stated that pregnancy cases increase in the third week, following the full moon. This fact isn't considered as a strange one if we realize that this phenomenon can be noticed among animals, and many other creatures that depend on the moon in their biological cycle. This fact urged the scientists to assume that the full moon promotes the secretion of more hormones.

Based on the previous studies that are related to the moon and its completion as well as Its effect on the human body, the following question is being asked: Do the electromagnetic waves at full moon affect functional organs of the human being? the fact that the full moon causes the tides which have an evident impact on large surfaces of water such as seas and oceans leads us to another question, is the impact of tides, which results from the moon, limited only to the large surfaces of water or it includes the small surfaces too; knowing that the percentage of water in blood is $83 \%$, in muscles is $73 \%$, in the body fat is $25 \%$ and in the bones is $22 \%$, which means that the percentage of water in the human body reaches about two-thirds of the human size. And so, this study is designed to answer the question that relate to the impact of electromagnetic waves at full moon on some physiological changes.

\section{The study objectives:}

This study aims at identifying the following:-

- The existence of statistically significant differences between the pre and post measurements for the study variables of (heart pulse, blood glucose, systolic blood pressure and diastolic blood pressure).

- The existence of statistically significant differences between the pre and post measurements for the study variables of (heart pulse, blood glucose, systolic blood pressure and diastolic blood pressure) with regard to the variables of gender and age. 


\section{MIl Macrothink}

\section{The study questions:}

- Are there statistically significant differences between the pre and post measurements for the study variables of ((heart pulse, blood glucose, systolic blood pressure and diastolic blood pressure).

-Are there statistically significant differences between the pre and post measurements for the study variables of (heart pulse, blood glucose, systolic blood pressure and diastolic blood pressure) with regard to the variables of gender and age.

\section{Literature review (previous studies)}

Introduction:

These days, after the development in physics and astronomy, we witness a return to the study of the impact of the moon on us since we are equipped with accurate and objective means and we are also driven by the same old intuitive idea. Scientists discovered that the earth magnetism and the space ionization differ and change according to the moon phases.

First, the studies about the impact of full moon on the human beings:

Both of Lieber,and Sherin (1972) conducted a study that aimed to identify the relationship between the lunar gravity and mood disorder. The study found that it is evident that the moon, with its gravitational impact on the earth, is the main contributor for ocean, space and earth tides. If we look at the human body as a microcosm which is composed of the same elements that make up the earth surface (80\% of water and $20 \%$ of organic and mineral salts), it becomes clear that the force of the lunar gravity is able to have a similar effect on the water that is contained in the human body. Thus, the moon can make periodic alterations on the liquid area in which our body cells swim, so that we may talk about the biological tides that make changes in the mood of people who suffer from conduct behavior.

Ravitz (1960) conducted a study which aims to identify the impact of electromagnetic charge that result from the changes in the phases of the moon on the psychiatric patients. In order to do so, he measured the variation in the electric potential between the head and the chest among psychiatric patients. The study showed that the electromagnetic charges that the body emits are affected by the moon phases as it revolves around the earth through which the charges reach the highest amount at the full moon. The study also suggested that the difference changes on a daily basis regarding to the changes of the moon phases and the frenzy of patients. The study found that the moon does not directly affect on the human behavior, but it changes the proportions of the electromagnetic forces in the cosmos, and that leads to troubles among the imbalanced people.

A team of researchers at the University of Miami, led by the psychiatrist, Leiber (1970) conducted a study that aimed to identify the relationship between the moon and the murder crimes. Those researchers traced all the murder crimes that took place during the period of fifteen years at Dade County in the state of Florida. After reviewing all the details and information about the murder crimes, the study found that there are about (2000) homicide crimes. Based on the results of the analysis of these crimes. The researchers found 
that the rate for murder crimes decreases and increases according to the moon phases, particularly, the researchers found that the rate of murder crimes increases during the phase of the full moon as well as the phase of new moon. While the rates of crimes decrease during the other stages of the lunar cycle. In order to confirm their findings, the researchers conducted their study in another American state.

Badis (2008)conducted a study that aims at identifying the occurrence of epilepsy and seizures during the full moon, The study sample consisted of 800 patients with epilepsy during the period of three years The study results found that there is a relationship between the moon phases during the lunar cycle and the rate of the occurrence of epileptic seizures The study also concluded that there are psychological seizures, but not epilepsy.

Andrews (1998), conducted a study that aims to identify the cases of acute bleeding, after the operations of tonsillectomy and their relation with the moon phases during the lunar month cycle. The study sample consisted of (1000) tonsillectomy cases. The study found that there is a relationship between the cases of acute bleeding, after tonsillectomy operations and the evolution of the moon phases during the days of the lunar month. The study shows that $82 \%$ of acute bleeding cases take place during the days of the full moon, when compared with the days of the moon disappearance.

Second, the studies about the impact of electromagnetic charges on the human beings:

Al-Qudah 2013 conducted a study which aimed to identify the heart pulse rate during the time of rest with regard to the following magnetic directions: North, South, East, West as well as the direction of the center of the land on the earth. The study sample consisted of 122 volunteers of the healthy male who agreed to participate. The heart pulse rate at rest was measured in the standard conditions for the proposed directions in the posture of lying on the back with the eyes closed. The duration of the interval between each two directions was (5) minutes. The results of the study showed that there are explicit differences with regard to the study variables in favor of the measurement on the direction of the center of the land. The researcher concluded that the measurement at the direction of the center of the land gives the lowest readings at the level of heart pulse rate at the time ofrest.

Beischer \& Miller (1962), conducted a study which aimed to determine the impact of the low-intensity magnetic field on the human beings. The study sample consisted of six healthy male volunteers whose age ranged between (17-19) years old during a period of twenty days. The researchers divided the sample into two groups: the first group is the experimental group which consisted of four volunteers who were exposed to the lowintensity magnetic field (one out of a thousand of the normal earth's magnetic field intensity ) during the period of ten consecutive days. The second group is the control group which consisted of two volunteers who were exposed to the normal earth magnetic field during a period of twenty-one days. The two groups were exposed to the same system of sleeping, rest, food and physical efforts. The rate of heart pulse was observed by palpating on the wrist, arterial systolic and diastolic blood pressure, breathing rate, body temperature - from 
the mouth- electrocardiography, body weight, and other measurements. The results of the study showed a general increase in the readings of the two groups, especially in the first five days with regard to weight, breathing rate and heart pulse rate at rest (with an increase of one pulse per a day during 21 days), while, a decline has been observed in the rate of systolic blood pressure in the first experimental group with a relative stability in the diastolic pressure. The results also showed that there are statistically significant differences at the level of the physiological variables average in the post readings between the two groups in favor of the first experimental group, where the average of vitality readings was less among the second control group.

Eisa (2010) conducted a study which aimed to identify the impact of using multifrequency and broad-spectrum magnetic fields on the treatment of lower back pain. The study sample consisted of seven athletes who suffer from myogenic back pain,. They were exposed to an artificial multi- frequency and broad-spectrum magnetic field by using a Beamer mattress / model 3000 and a local intensifier - which give a perfect magnetic field that is similar to the earth's magnetic field.The results of the study showed statistically significant improvement at the level of the temperature of some related muscles as well as their strength, flexibility and pain threshold. The researcher recommended to use the proposed treatment program which is based on multi- frequency and broad-spectrum electromagnetic field in the treatment of myogenic lower back pain among athletes.

\section{Commentary of the previous studies:}

Based on the above review of the previous studies and researches, it becomes evident that these studies are interested in studying the impact of electromagnetic waves at the full moon, whether that impact was on the psychological level, the ratio of criminality, epilepsy seizures or as an increase of the birth rates. Recently, there has been an increasing interest in studying the effect of electromagnetic waves at the full moon on the physiological aspects, but these studies are still rare.

Based on the literature of the previous studies, the following results could be concluded:

1. The previous studies agreed on the effect of electromagnetic waves on human beings at the full moon.

2- The researcher made use of these studies as follow:

$\square$ deeper identification and understanding of the problem of the study.

$\square$ formulating the objectives and the questions of the study.

$\square$ measurement methods as well as the needed tools for the purposes of the study.

$\square$ choosing the appropriate methodology for the study objectives, as well as the appropriate statistical methods in order to answer the questions of the study.

The researcher believes that his study is distinguished from the previous studies as::

It is one of the first studies that addressed the effect of electromagnetic waves at the full 
moon on some physiological variables..

-It also varies according to the methods and procedures by which the data of the study have been collected.

\section{The study aspects:}

The current study was represented by the following aspects:

The human aspect: This study was limited to the students of the Faculty of Sports Science at the University of M'utah.

Temporal aspect data which are related to the study were collected in 2013

Geographical area: this study was applied at the Faculty of Sport Sciences at the University of Mu'tah.

Methodology and study methods (the methods and procedures)

The study methodology :the descriptive approach was used by following the methods of a survey study with its steps and scientific procedures due to its compatibility to the nature of this study.

\section{The study community and sample:}

The study community consisted of all the students in the faculty of sports sciences at Mu'tah university with about (1300) students.

\section{The study sample}

The study sample consisted of 20 students who were randomly chosen from the two departments in the faculty of sports sciences:

The department of sports rehabilitation

The department of physical education

Table (1) describes the study sample individuals by using the arithmetic means, the standard deviations as well as the highest and the lowest values of height, weight and age.

\begin{tabular}{|c|c|c|c|c|c|}
\hline $\begin{array}{c}\text { The lowest } \\
\text { value }\end{array}$ & $\begin{array}{c}\text { The highest } \\
\text { value }\end{array}$ & $\begin{array}{c}\text { Standard } \\
\text { deviation }\end{array}$ & Mean & Number & $\begin{array}{c}\text { Physical } \\
\text { variables }\end{array}$ \\
\hline 19.00 & 23.00 & 1.15166 & 20.2000 & 20 & Age \\
\hline 150.00 & 192.00 & 11.92201 & 1.6885 & 20 & Height \\
\hline 43.00 & 102.00 & 13.50915 & 59.9474 & 20 & Weight \\
\hline
\end{tabular}

\section{The study variables:}

First.: Independent variables which include:

-Electromagnetic waves at the full moon 
Second : The dependent variables which include:

1- Heart pulse (rate of heart beats)

2- Blood glucose

3- systolic blood pressure

4- diastolic blood pressure

The study tools and tests: the following tools and tests have been used:

1- a device for measuring blood pressure (micro life type)

2. a device for measuring heart pulse(micro life type)

3- a device for measuring blood sugar (blood glucose) (Accu-check Active tybe)

4- Weight scale

5-height tape measure.

6- clock timer

The statistical methods: a number of statistical methods have been used in order to answer the questions of the study, these are:(arithmetic means, standard deviations, T-test Independent Samples, Pearson correlation coefficient test.

\section{The scientific coefficients of the tests:}

The validity and reliability of the tool : a number of tests and supporting tools which proved validity and reliability for measurement in the field of sports have been used. These tests are considered as standardized tests and the validity of these tests became confident with regard to the measurement, besides depending on some points of views of the experts in this field.

Steps for conducting the study (the field procedures for the search of the study:

Organizational procedures:

The study was conducted as follow:

$\square$ The researcher and his assistants took the physical measurements (height, weight, and the biochemical tests have also been taken (blood glucose)

- The measurement of the blood pressure was applied to the study sample by using a device for measuring pressure (micro life device) with the individuals sitting towards A- Qiblah direction.

$\square$ the measurement of the heart pulse was applied to the sample by using a device for measuring the heart pulse of the (micro life) type

\section{The study seeks to answer the following questions:}

The first question: Are there statistically significant differences between the pre and post measurement regarding to the physiological variables of (heart pulse / blood glucose / systolic blood pressure and diastolic blood pressure)?

Table (2) illustrates the means, the standard deviations, T-test results for the related 
measurement (T-test independent samples) for the difference significance with regard to heart pulse for the pre and post measurement.

\begin{tabular}{|c|c|c|c|c|c|c|}
\hline $\begin{array}{l}\text { Significance } \\
\text { level }\end{array}$ & $\begin{array}{l}\mathbf{T} \\
\text { value }\end{array}$ & $\begin{array}{l}\text { Standard } \\
\text { deviation }\end{array}$ & Mean & $\begin{array}{l}\text { degrees of } \\
\text { freedom }\end{array}$ & Measure & Variable \\
\hline \multirow[b]{2}{*}{0.823} & \multirow[b]{2}{*}{-0.227} & 13.44666 & 78.3167 & \multirow[b]{2}{*}{19} & pre & \multirow{2}{*}{$\begin{array}{l}\text { Heart } \\
\text { pulse }\end{array}$} \\
\hline & & 10.02978 & 78.6667 & & post & \\
\hline
\end{tabular}

Table (2) illustrates that there are no statistically significant differences between the pre and post measurements with regard to the variable of heart pulse at the significance level of $(\alpha \leq 0.05)$ in which the calculated value of T-test for the pre and post measurement was $(0.227)$ and the value of the significance level was $(0.823)$.The results of the arithmetic mean show that there is a little priority for the post measurement, where the value of the post measurement was (78.6667) and the value of the pre measurement was (78.3167).

Table (3) illustrates the means, the standard deviations, T-test results for the related measurement (T-test independent samples) for the difference significance of blood glucose for the pre and post measurement.

\begin{tabular}{|c|c|c|c|c|c|c|}
\hline $\begin{array}{c}\text { Significance } \\
\text { level }\end{array}$ & value T & $\begin{array}{c}\text { Standard } \\
\text { deviation }\end{array}$ & Mean & $\begin{array}{c}\text { degrees of } \\
\text { freedom }\end{array}$ & Measure & Variable \\
\cline { 1 - 5 } 0.617 & $-0.509-$ & 9.93488 & 84.3333 & 19 & post & $\begin{array}{c}\text { Blood } \\
\text { glucose }\end{array}$ \\
\cline { 1 - 5 } & & 10.09927 & 83.0667 & 19 & pre \\
\hline
\end{tabular}

Table (3) illustrates that there are no statistically significant differences between the pre and post measurements with regard to the variable of blood glucose at the significance level of $(\alpha \leq 0.05)$ in which the calculated value of T-test for the pre and post measurement was (-.509) and the value of the significance level was (0.167).The results of the arithmetic mean show that there is a priority for the post measurement, where the value of the post measurement was (84.3333) and the value of the pre measurement was (83.0667). 
Table (4) illustrates the means, the standard deviations, T-test results for the related measurement (T-test independent samples) for the difference significance of Systolic pressure for the pre and post measurement.

\begin{tabular}{|c|c|c|c|c|c|c|}
\hline $\begin{array}{c}\text { Significance } \\
\text { level }\end{array}$ & value T & $\begin{array}{c}\text { Standard } \\
\text { deviation }\end{array}$ & Mean & $\begin{array}{c}\text { degrees of } \\
\text { freedom }\end{array}$ & Measure & Variable \\
\hline \multirow{2}{*}{0.791} & $-0.269-$ & 9.40020 & 1.1623 & 19 & pre & $\begin{array}{c}\text { Systolic } \\
\text { pressure }\end{array}$ \\
\hline
\end{tabular}

Table (4) illustrates that there are no statistically significant differences between the pre and post measurements with regard to the variable of Systolic pressure at the significance level of $(\alpha \leq 0.05)$ in which the calculated value of T-test for the pre and post measurement was (-0.269) and the value of the significance level was (0.791). The results of the arithmetic mean show that there is a priority for the post measurement, where the value of the post measurement was (1.1707) and the value of the pre measurement was (1.1623).

Table (5) illustrates the means, the standard deviations, T-test results for the related measurement (T-test independent samples) for the difference significance of diastolic pressure for the pre and post measurement.

\begin{tabular}{|c|c|c|c|c|c|c|}
\hline $\begin{array}{c}\text { Significance } \\
\text { level }\end{array}$ & $\begin{array}{c}\text { T } \\
\text { value }\end{array}$ & $\begin{array}{c}\text { Standard } \\
\text { deviation }\end{array}$ & Mean & $\begin{array}{c}\text { degrees of } \\
\text { freedom }\end{array}$ & Measure & Variable \\
\hline 0.178 & 1.399 & 7.39043 & 74.4167 & 19 & pre & diastolic \\
\cline { 3 - 6 } & 7.64358 & 72.2833 & 19 & post & pressure \\
\hline
\end{tabular}

Table (5) illustrates that there are no statistically significant differences between the pre and post measurements with regard to the variable of diastolic pressure at the significance level of $(\alpha \leq 0.05)$ in which the calculated value of T-test for the pre and post measurement was (1.399) and the value of the significance level was (0.178). The results of the arithmetic mean show that there is a little priority for the pre measurement, where the value of the pre measurement was (74.4167) and the value of the post measurement was (72.2833).

The second question: Are there statistically significant differences between the pre and post measurements regarding to the physiological variables of (heart pulse / blood glucose / systolic blood pressure and diastolic blood pressure) with regard to the variable of gender and age ?

Gender variable: The arithmetic means, the standard deviations and the T- test results for the related measurements (T-test independent samples) were used for the significance of the difference in the heart pulse for the pre and post measurements.

Table (6) illustrates the means, the standard deviations, T-test results for the related 
measurement (T-test independent samples) for the difference significance with regard to heart pulse for the pre and post measurement regarding to the variable of gender

\begin{tabular}{|c|c|c|c|c|c|c|}
\hline $\begin{array}{c}\text { Significance } \\
\text { level }\end{array}$ & T value & $\begin{array}{c}\text { Standard } \\
\text { deviation }\end{array}$ & Mean & $\begin{array}{c}\text { degrees of } \\
\text { freedom }\end{array}$ & Measure & Variable \\
\hline$* 0.021$ & $-2.532-$ & 13.49890 & 86.5417 & 8 & $\begin{array}{c}\text { Pre } \\
\text { female }\end{array}$ & $\begin{array}{c}\text { heart } \\
\text { pulse }\end{array}$ \\
\cline { 3 - 6 } 0.053 & $-2.070-$ & 8.85974 & 75.1667 & 12 & $\begin{array}{c}\text { Post } \\
\text { male }\end{array}$ & $\begin{array}{c}\text { heart } \\
\text { pulse }\end{array}$ \\
\cline { 3 - 6 } & & 9.85893 & 83.9167 & 8 & $\begin{array}{c}\text { Post } \\
\text { female }\end{array}$ & Pre male \\
\hline
\end{tabular}

Table (6) illustrates that there are statistically significant differences in the pre measurements between males and females for the heart pulse variable at the significance level of $(\alpha \leq 0.05)$ in which the calculated value of T-test for the pre measurement was $(-2.532)$ and the value of the significance level was (0.021)in favor of the pre measurement for females with a mean of (86.5417). While the mean of the pre measurement for males was (72.8333)

While the table illustrates that there are no statistically significant differences in the post measurements between males and females for the heart pulse variable at the significance level of $(\alpha \leq 0.05)$ in which the calculated value of T-test for the post measurement was (2.070) and the value of the significance level was (0.053).

The scientific studies proved that the magnetic tension has an evident impact on people's health and on the Physiological variables such as the rate of rest pulse. When a disorder occurs within the magnetic field, it may cause a decline in the vital operations, which appear in the form of tension in the function of the blood circulatory system which is represented by an increase in the rate of rest pulse. This conclusion is consistent with the finding of the study of Beischer \& Miller, (1962)

Which concludes that the rate of rest pulse increases in a statistically significant manner as a respond to the decrease in the magnetic field to which the experimental group was exposed.

The study attributed that to the impact of the low-intensity magnetic field which causes physiological obstacles that lead to an increase in the rate of heart pulse at rest.

The researcher attributes these differences in the pre measurement to the variable of heart pulse between males and females in favor of females. And this is a logical result because the heart pulse decreases at rest as the size of the body increases. For example, the elephant and the whale which are the biggest creatures on the earth have less heart pulse rate than the other smaller creatures, while the mouse and the rabbit are regarded as small, when compared to man. Therefore, the heart pulse rate for these animals is faster than the heart pulse rate of man (Haza', 2009) 


\section{Ml Macrothink}

Based on the previous mentioned data, this conclusion is considered as a logical one because the males are bigger than the females regarding to their size, which means that the heart pulse rate of females is more than that of males; females have less muscular mass than males. Thus, a female body mass is less than that of a male, so this is consistent with the prementioned rule that " when the size of the body increases, the heart pulse rate decreases at the time of rest.

The researcher attributes the absence of these differences in the post measurements to the variable of heart pulse between males and females as females are more affected by the electromagnetic waves that come from the moon.

Table (7) illustrates the means, the standard deviations, T-test results for the related measurement (T-test independent samples) for the difference significance with regard to blood glucose for the pre and post measurement regarding to the variable of gender

\begin{tabular}{|c|c|c|c|c|c|c|}
\hline $\begin{array}{l}\text { Significance } \\
\text { level }\end{array}$ & $\begin{array}{l}\mathbf{T} \\
\text { value }\end{array}$ & $\begin{array}{l}\text { Standard } \\
\text { deviation }\end{array}$ & Mean & $\begin{array}{l}\text { Degrees } \\
\text { Of } \\
\text { freedom }\end{array}$ & Measure & Variable \\
\hline \multirow{2}{*}{0.507} & \multirow{2}{*}{0.0677} & 7.333333 & 84.3333 & 12 & Pre (male) & \multirow{2}{*}{$\begin{array}{l}\text { blood } \\
\text { glucose }\end{array}$} \\
\hline & & 13.61838 & 81.1667 & 8 & Pre (female) & \\
\hline \multirow{2}{*}{0.230} & \multirow{2}{*}{1.243} & 6.76344 .8 & 86.5556 & 12 & Post (male) & \multirow{2}{*}{$\begin{array}{l}\text { blood } \\
\text { glucose }\end{array}$} \\
\hline & & 13.22336 & 81.0000 & 8 & Post (female) & \\
\hline
\end{tabular}

Table (7) illustrates that there are no statistically significant differences in the pre measurements between males and females for the blood glucose variable at the significance level of $(\alpha \leq 0.05)$ in which the calculated value of T-test for the pre measurement was (0677) and the value of the significance level was (0.507).

The table also illustrates that there are no statistically significant differences in the post measurements between males and females for the blood glucose variable at the significance level of $(\alpha \leq 0.05)$ in which the calculated value of T-test for the post measurement was (1.243) and the value of the significance level was (0.230). 
Table (8) illustrates the means, the standard deviations, T-test results for the related measurement (T-test independent samples) for the difference significance with regard to systolic blood pressure for the pre and post measurement regarding to the variable of gender

\begin{tabular}{|c|c|c|c|c|c|c|}
\hline $\begin{array}{l}\text { Significance } \\
\text { level }\end{array}$ & $\begin{array}{l}\text { T } \\
\text { value }\end{array}$ & $\begin{array}{l}\text { Standard } \\
\text { deviation }\end{array}$ & Mean & $\begin{array}{l}\text { degrees of } \\
\text { freedom }\end{array}$ & Measure & Variable \\
\hline \multirow{2}{*}{0.332} & \multirow{2}{*}{0.997} & 8.76844 & 1.1794 & 12 & Pre (male) & \multirow{2}{*}{$\begin{array}{l}\text { systolic blood } \\
\text { pressure }\end{array}$} \\
\hline & & 10.31873 & 1.1367 & 8 & Pre (female) & \\
\hline \multirow{2}{*}{0.463} & \multirow{2}{*}{$\begin{array}{l}- \\
0.750-\end{array}$} & 5.05025 & 1.1550 & 12 & Post male & \multirow{2}{*}{$\begin{array}{l}\text { systolic blood } \\
\text { pressure }\end{array}$} \\
\hline & & 17.21272 & 1.1942 & 8 & Post female & \\
\hline
\end{tabular}

Table (8) illustrates that there are no statistically significant differences in the pre measurements between males and females for the systolic blood pressure variable at the significance level of $(\alpha \leq 0.05)$ in which the calculated value of T-test for the pre measurement was (0.997) and the value of the significance level was (0.332). The table also illustrates that there are no statistically significant differences in the post measurements between males and females for the systolic blood pressure variable at the significance level of $(\alpha \leq 0.05)$ in which the calculated value of T-test for the post measurement was (-.750) and the value of the significance level was (0.463).

Table (9) illustrates the means, the standard deviations, T-test results for the related measurement (T-test independent samples) for the difference significance with regard to diastolic blood pressure for the pre and post measurement regarding to the variable of gender

\begin{tabular}{|c|c|c|c|c|c|c|}
\hline $\begin{array}{l}\text { Significance } \\
\text { level }\end{array}$ & $\begin{array}{l}\mathbf{T} \\
\text { value }\end{array}$ & $\begin{array}{l}\text { Standard } \\
\text { deviation }\end{array}$ & Mean & $\begin{array}{l}\text { degree of } \\
\text { freedom }\end{array}$ & Measure & Variable \\
\hline \multirow{2}{*}{0.606} & \multirow{2}{*}{$-0.525-$} & 7.55914 & 73.6944 & 12 & $\begin{array}{l}\text { Pre } \\
\text { (male) }\end{array}$ & \multirow{2}{*}{$\begin{array}{l}\text { Diastolic } \\
\text { blood } \\
\text { pressure }\end{array}$} \\
\hline & & 7.49815 & 75.5000 & 8 & $\begin{array}{l}\text { Pre } \\
\text { (female) }\end{array}$ & \\
\hline \multirow{2}{*}{0.065} & \multirow{2}{*}{$\begin{array}{l}- \\
1.969-\end{array}$} & 6.18541 & 69.7222 & 12 & Post male & \multirow{2}{*}{$\begin{array}{l}\text { Diastolic } \\
\text { blood } \\
\text { pressure }\end{array}$} \\
\hline & & 8.38733 & 76.1250 & 8 & $\begin{array}{l}\text { Post } \\
\text { female }\end{array}$ & \\
\hline
\end{tabular}

Table (9) illustrates that there are no statistically significant differences in the pre measurements between males and females for the diastolic blood pressure variable at the 
significance level of $(\alpha \leq 0.05)$ in which the calculated value of T-test for the pre measurement was (-0.525) and the value of the significance level was (0.606) the table also illustrates that there are no statistically significant differences in the post measurements between males and females for the diastolic blood pressure variable at the significance level of $(\alpha \leq 0.05)$ in which the calculated value of T-test for the post measurement was (-1.969) and the value of the significance level was (0.065).

The variable of age: The results of Pearson correlation coefficient test for the pre and post measurement were used for heart pulse.

Table (10) illustrates the results of Pearson correlation coefficient test for the pre and post measurement for heart pulse regarding to the variable of age

\begin{tabular}{|l|l|l|l|l|c|}
\hline $\begin{array}{l}\text { Significance } \\
\text { level }\end{array}$ & $\begin{array}{l}\text { correlation } \\
\text { coefficient }\end{array}$ & $\begin{array}{l}\text { degree of } \\
\text { freedom }\end{array}$ & Measure & Variable & \\
\cline { 1 - 4 } 0.721 & 0.085 & \multirow{2}{*}{19} & pre & $\begin{array}{l}\text { Heart } \\
\text { pulse }\end{array}$ & \multirow{8}{\&}{} \\
\cline { 1 - 2 } 0.874 & 0.038 & post & \\
\hline
\end{tabular}

Table (10) illustrates that there are no statistically significant differences in the pre and post measurement for the heart pulse depending on the variable of age at the significance level of $(\alpha \leq 0.05)$ as the value of Pearson correlation coefficient for the pre measurement was(0.085), and the value of the significance level was (0.721). The value of the Pearson correlation coefficient for the post measurement was (0.038), and the value of the significance level was (0.874).This result indicates that there is a significant correlation between pre and post measurement for heart pulse, which means that, there was no effect of the waves generated by the full moon regarding to the variable of age.

Table (11) illustrates the results of Pearson correlation coefficient test for the pre and post measurement for blood glucose regarding to the variable of age

\begin{tabular}{|l|l|l|l|l|l|}
\hline $\begin{array}{l}\text { Significance } \\
\text { level }\end{array}$ & $\begin{array}{l}\text { correlation } \\
\text { coefficient }\end{array}$ & $\begin{array}{l}\text { degree of } \\
\text { freedom }\end{array}$ & Measure & Variable & \\
\cline { 1 - 2 } 0.273 & $-0.258-$ & \multirow{2}{*}{19} & pre & $\begin{array}{l}\text { blood } \\
\text { glucose }\end{array}$ & \multirow{8}{\varangle}{} \\
\cline { 1 - 2 } & $-0.549^{*}$ & & post & \\
\hline
\end{tabular}

Table

(11) illustrates that there are statistically significant differences in the pre and post measurement for the blood glucose depending on the variable of age at the significance level of $(\alpha \leq 0.05)$ as the value of Pearson correlation coefficient for the pre measurement was($0.258)$, and the value of the significance level was (0.273). The value of the Pearson correlation coefficient for the post measurement was (0.549), and the value of the significance level was (0.012). This result indicates that there is a significant effect of the waves generated by the full moon regarding to the variable of age in favor of the post measurement 
Table (12) illustrates the results of Pearson correlation coefficient test for the pre and post measurement for systolic blood pressure regarding to the variable of age

\begin{tabular}{|c|c|c|c|c|c|}
\hline $\begin{array}{l}\text { Significance } \\
\text { level }\end{array}$ & $\begin{array}{l}\text { correlation } \\
\text { coefficient }\end{array}$ & $\begin{array}{l}\text { degree of } \\
\text { freedom }\end{array}$ & Measure & Variable & \\
\hline 0.963 & $-0.011-$ & \multirow[t]{2}{*}{19} & pre & \multirow{2}{*}{$\begin{array}{l}\text { systolic } \\
\text { blood } \\
\text { pressure }\end{array}$} & \\
\hline 0.463 & 0.174 & & post & & $\underbrace{\infty}_{\pi}$ \\
\hline
\end{tabular}

Table

(12) illustrates that there are no statistically significant differences in the pre and post measurement for the systolic blood pressure depending on the variable of age at the significance level of $(\alpha \leq 0.05)$ as the value of Pearson correlation coefficient for the pre measurement was(-011)., and the value of the significance level was (0.963). The value of the Pearson correlation coefficient for the post measurement was (0.174), and the value of the significance level was (0.463).This result indicates that there is a significant correlation between pre and post measurement for systolic blood pressure. While the results indicate that systolic blood pressure decreases as the age increases in the pre measurement. These results also showed that systolic blood pressure wasn't affected in the post measurement.

Table (13) illustrates the results of Pearson correlation coefficient test for the pre and post measurement for diastolic blood pressure regarding to the variable of age

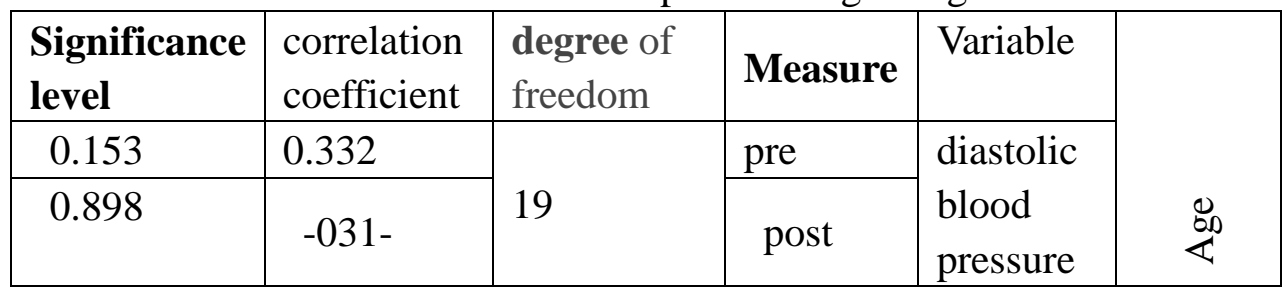

Table (13) illustrates that there are no statistically significant differences in the pre and post measurement for the diastolic blood pressure depending on the variable of age at the significance level of $(\alpha \leq 0.05)$ as the value of Pearson correlation coefficient for the pre measurement was(0.332), and the value of the significance level was (0.153). The value of the Pearson correlation coefficient for the post measurement was (-031), and the value of the significance level was (0.898).This result indicates that there is a significant correlation between pre and post measurement for diastolic blood pressure. While the results indicate that dialostic blood pressure decreases as the age increases in the post measurement. These results also showed that systolic blood pressure wasn't affected in the pre measurement.

Conclusions and recommendations :

\section{$\square$ Conclusions:}

1. There is no direct effect of the electromagnetic waves that are emitted from the full moon on each of the physiological variables that are being studied.

2. The electromagnetic waves that are emitted at the full moon, Cause outweigh to 


\section{Macrothink}

the arithmetic means of the different physiological variables being studied.

3. the heart pulse of females is significantly affected when it is measured during the days of the full moon due to the electromagnetic waves that are emitted from the full moon.

4. There was no effect of the waves that are emitted from the full moon according to the variable of age on the physiological variables of ( heart pulse, systolic blood pressure, and diastolic blood pressure)

5. The electromagnetic waves that are emitted from the full moon affect blood glucose.

6. Females are affected by the electromagnetic waves that are emitted from the full moon.

\section{Recommendations:}

In the light of the study results, the study recommends to:

1. Not to rely on the reading of the heart pulse during the days of the full moon as an indicator of the heart pulse, especially for females.

2. Conduct a similar study in which the sample consists of more individuals of both males and females .

3. Conduct several similar studies in different places with ( hot and cold climates ) or ( high and low altitudes ).

\section{References :}

-Beischer, D. E., and Miller, E. F. I I , (1962), Exposure of man to low intensity magnetic fields, NSAM-823. NASA Order No. R-39. Pensacola, Fla.: Naval School of Aviation Medicine.

- Eisa, Rima Nabil Mousa (2010). "The impact of using the magnetic fields in the treatment of myogenic lower back pain for athletes." Unpublished master thesis, the University of Jordan Amman, Jordan.

- Al Hazza' , Hazza' Bin Mohammed (2009), Exercise Physiology: the theoretical foundations and of the laboratory procedures for the physiological measurements, AlRiyadh: King Saud University.

- Ravitz, Leonard (1960), the electromagnetic charges that the body emits are affected by the magnetic field of the earth, Duke University, U.S.A .

- Lieber Arnold, and Sherin Carolyn (1972), the relationship between the full moon and the clinical psychological diseases, the University of Miami.

- Researchers from the Center for Health Sciences (2004), scientific reviews of the relationship between the full moon and organic diseases, at the University of South Florida. 
- Andrews, Edison (1998), the relationship between the cases of acute bleeding after tonsillectomy operations and the evolution of the appearance of the moon during the days of the lunar month, the Journal of the Florida Medical Association.

- A group of scientists from various countries around the world (2005), Astronomy, Space and atmosphere Sciences in the developed countries and the third world, the Office for Outer Space Affairs - the United Nations.

- Researchers from North Carolina (2005), the impact of the full moon on the increase of the rates of births, the American Journal of gynecology and obstetrics.

- Medicine (1987), impacts of the full moon on people's behavior, the journal of emergency medicine.

- Bin Badis and Saleem (2008), the occurrence of epileptic seizures is not more common during the full moon. University of Southern Florida.

- policy newspaper (2009), the planets have a direct impact on human health as well as the nature of his thinking, an article.

- Noaimi, Humid Mujuil (2005), astronomy and astrology, (www.falak.ae).

- Leiber (1970), the relationship between the full moon and murder crimes, the American Journal of Psychiatry.

- Mohsen, Nabil (2010), cosmic psychology, Aleppo - Syria.

- Sa'adia, Dalal (2013), energy therapy .

- Al-Qudah (2013), to study aimed to identify resting pulse in the measurement of magnetic trends, the fifth conference creativity Sports University of Jordan. 